\title{
PANDEMICS AND DISASTER PLANNING IN NURSING FACILITIES
}

On her way to work, Sue Wells, the social worker at Grove Nursing Center, had heard that the weather was going to turn stormy in the late afternoon. Proactive in many areas of her life, Sue had a four-wheel-drive car and emergency provisions, including some high-energy snacks, water, and a medical kit, for her commute to work. However, Sue did not know the disaster plans for the residents of her facility. The preannounced storm struck the area with great ferocity; high winds, hail, and torrential rain brought severe local flooding. By noontime that day, Grove Nursing Center had lost part of its roof and several staff members lost their cars in the flash flooding that followed. With only sections of the facility operational, the administrator's decision, after consultation with state officials, was to evacuate the nursing facility's 110 residents.

Since the Northridge earthquake in 1994; the September 11, 2001, attack; Hurricane Katrina in 2005; the earthquake in Haiti in 2010; the tsunami nuclear disaster in Japan in 2011; and the tornadoes in the southern United States that claimed almost 200 lives in 2011, the world is becoming more familiar with the fact that disaster occurs somewhere almost daily. These events, both in America and abroad, have provided us with some insight into the unique difficulties of older adults, particularly those who are in nursing facilities. At the same time, multiple-casualty events in the United States are rare by world standards; the vast majority of catastrophes have resulted in fewer than 100 fatalities. With the exception of the events in 2001 (September 11 attack) and 2005 (Hurricane Katrina), the greatest loss of life occurred in 1941 at Pearl Harbor. This knowledge can impact decision-making for frail elders at the nursing facility level. An administrator needs to weigh all the facts and consider whether to have residents remain in 
a facility, to "shelter in place," or to evacuate, which would include obtaining the necessary bus/ambulance transportation to evacuation centers, ensuring that all medical information and caregiving equipment/medications are available, and maintaining communication with both residents and families. Either decision can have serious consequences for residents.

In the case of Hurricane Katrina in 2005, the owners of a small nursing home, Sal and Mabel Mangano, determined that they would "shelter in place" rather than evacuate their frail residents. Unfortunately, this action turned out to be the wrong decision and 35 residents died in the following storm surge (Parker, 2005). In Texas (2005), a planned evacuation from a facility called Brighton Gardens ended tragically. The bus carrying 37 passengers and six healthcare workers was caught in lengthy traffic jams. It ignited, killing 23 residents. The probable cause of this fire was determined to be a lack of lubrication of the rear bus axle (Langford, 2009). In both of these cases, the determination to evacuate was handled differently; yet in both cases, a tragedy occurred.

\section{WHAT ARE COMMON EMERGENCY/DISASTER CODES USED IN A FACILITY?}

Local areas often use sirens to alert residents of an impending problem (nuclear power plant issue, tornado, etc.). To provide information to key staff and to avoid panic, medical emergencies in institutional settings are provided in code. Staff members are often informed of these disaster codes during the standard orientation process. Periodically, these are reviewed as a part of the nursing facility policy. These commonly used code words are often used in facilities over intercoms and emergency systems.

\begin{tabular}{|l|l|}
\hline CODE WORD & DESIGNATED EMERGENCY \\
\hline Code Red & Fire \\
\hline Code Blue & Doctor \\
\hline Code Brown & Bomb threat \\
\hline Code Yellow & Tornado \\
\hline
\end{tabular}

\section{WHAT IS CONSIDERED A MAJOR DISASTER?}

Disaster is a label determined after an event. Often, local newscasters can make almost any weather event into a newsworthy story; from rain, sleet, 
snow, or high winds, the focus is on highlighting the problems because of the "weather" and making news exciting: The reporter is often shown by a snowy road, by swirling waters, or by downed tree limbs and power lines. These can be individually dangerous or annoying, but they are not "disasters."

True disasters have a formal definition. A major disaster is defined as any natural catastrophe or, regardless of cause, any fire, flood, or explosion, in any part of the United States, which in the determination of the president causes damage of sufficient severity and magnitude to warrant major disaster assistance under the Stafford Act to supplement the efforts and available resources of states, local governments, and disaster relief organizations in alleviating damage, loss, hardship, or suffering (Cornell Law School, 2000).

It can be very difficult to determine what is the best course of action in these circumstances because storms do not always proceed in anticipated directions, floods can take paths not anticipated, and fires can be managed before a crisis occurs. Thoughtful decision-making is essential on all levels, local, state, and federal, as well as when understanding the risks and benefits for frail residents regardless of the decision made.

\section{WHAT ARE NURSING FACILITIES SUPPOSED TO DO IN CASES OF DISASTER?}

In a major emergency situation, it is common knowledge that first responders can take as long as 72 hours or longer to reach survivors. Response systems (police, fire, hospitals and utility companies, etc.) are often overwhelmed within the initial aftermath of a widespread emergency. Thus, it is important for the carers of older adults to be prepared for a minimum of 72 hours following an event. Nursing homes are required to have resources, staff, supplies, food, water, and power to provide care during temporary storm/disaster conditions. These ancillary supplies when rationed among residents and attending staff can generally last approximately a week. In addition, hospitals and nursing facilities are required, by participating in Medicare and Medicaid programs, to provide an evacuation plan as a condition of participation. Although hospitals are specifically required to ensure patient safety, including developing plans that describe the safe transfer of patients to other healthcare settings, nursing homes are only required to have plans that meet all potential emergencies and disasters (no mention is made of actually transferring residents; Goolsby \& Mothershead, 2010).

When evacuation is necessary for nursing facilities, recent history has demonstrated that there can be challenges for nursing homes. Nursing home 
administrators can contact local and state officials for further directions regarding resident evacuation. However, there may be a host of difficulties, including problems with communication with local emergency managers, difficulty locating transportation suitable for evacuation of facility residents, and competition between healthcare settings for a limited number of vehicles appropriate for transportation to another setting and limited options for emergency evacuation (U.S. Government Accountability Office, 2006).

\section{WHAT IS THE ROLE OF THE SOCIAL WORKER IN AN EMERGENCY?}

As a member of the interdisciplinary staff, the social worker is knowledgeable about the residents, their preferences, and their family members. The facility emergency plan lists a role for every staff member, including the social worker. The social worker will be able to help during an emergency by:

- comforting residents who may become anxious or worried about the events;

- assisting other staff in organizing food, clothing, and/or paperwork;

- contacting families to assure them that residents are in good care and answering questions;

- contacting additional volunteers to assist residents, if staff are unable to get to the facility; and

- assisting staff in caring for residents as needed.

\section{WHAT IS THE ROLE OFTHE SOCIAL WORKER DURING A DISASTER?}

Being prepared for a crisis or a disaster is very helpful. Disasters are particularly arduous on older adults who are already compromised by chronic ailments. The movement from one healthcare setting to another under the best of circumstances can be difficult, but under the pressure of emergency evacuation, it can be traumatic. Social workers can work with the staff to minimize the impact of an emergency or emergency evacuation by preparing each resident for the next steps, making sure that all essential care items (including important personal objects, e.g., a blanket, beloved photo, or rosary beads) are sent with the person if a move is necessary, and ensuring that communication to the next setting is made completely and as smoothly as possible with appropriate follow-up. With thorough preparation and use 
of checklists, the social worker can ensure that the next caregiving setting has the key information to adequately care for the resident.

The degree of personal impact during a disaster is also very relevant as a response to the event(s). For example, for those who have experienced personal losses, such as the death of a victim of the disaster, the loss of a family member, or the destruction of one's home, another disaster may result in the person experiencing more anxiety, depression, posttraumatic stress disorder, somatic symptoms, and addictions (Toner et al., 2010).

\section{WHAT ARE SOME OF THE EMOTIONAL RESPONSESTO DISASTERS?}

During disasters, there are many emotional responses by all involved, and this includes the caregivers. The social worker should be aware that the psychiatric trauma of disaster and postemergency work could impede caregiving and put residents at risk. Knowing the range of emotional responses to disasters can be helpful. According to Lubit (2012), the four stages are as follows:

- Impact phase: The individual can feel stunned and experience a sense of numbness, fear, and possibly confusion.

- Crisis phase: Once the initial phase is over, the person may experience mixed emotions of denial and intrusive symptoms of hyperarousal. There may be somatic problems of fatigue, headaches, dizziness, or nausea.

- Resolution phase: This phase can include a person's feeling of grief, guilt, and depression.

- Reconstruction phase: During this phase, there is a reappraisal, an assignment of meaning, and integration of the event into a new self-concept.

\section{WHAT ARE THE EMERGENCY PLANS IN YOUR FACILITY?}

The facility social workers should clearly understand their role in the emergency plans of the facility. In most settings, there is a policy book where the specific emergency plans can be found. If the organization has an emergency plan, you should identify what role has been outlined for the social worker. In cases in which there is no policy or it is vague, the social worker should initiate a conversation with the administrator and director of nurses to develop one. These plans should be reviewed biannually for any changes (Joint Commission, 2005). 
According to the Centers for Medicare \& Medicaid Services (CMS), emergency plans should be made to meet the needs of the particular population they serve if essential services break down because of a disaster. Review

of the basic services necessary to meet a disaster is part of hazard analysis. These basic services may include the following:

- specific and clearly defined management and control procedures;

- specific actions to be taken for the hazard;

- staffing requirements and defined staff responsibilities;

- identification and maintenance of sufficient supplies and equipment to sustain operations and deliver care and services for at least 7 to 10 days (based on experiences from Hurricane Katrina, it is generally felt that the previous recommendation of 72 hours is no longer sufficient); and

- communication procedures to receive emergency warning/alerts and for communication with staff, families, and individuals receiving care before, during, and after the emergency (CMS, 2008).

In addition, there should be evacuation procedures that

- Identify who is responsible for implementing the facility evacuation plan.

- Identify how individuals receiving care, their families, staff, and others will be notified of the evacuation and communication methods that will be used during and after the evacuation.

- Identify staff responsibilities and how individuals will be cared for during evacuation.

- Identify a method to account for all individuals during and after the evacuation.

- Identify logistical support and preparation to move any medical documents, medication, food, water, or other necessary supplies and equipment needed to provide care and services for at least 7 to 10 days.

- Include transportation arrangements that are adequate for the individuals being served.

- Identify multiple evacuation locations, with one being at least 50 miles away, with suitable space, utilities, security, and sanitary facilities for individuals receiving care, staff, and others using the location (CMS, 2008).

\section{WHAT HAPPENED AT GROVE NURSING CENTER?}

The facility sustained structural damage and could not care for its residents safely; thus, the decision was made to evacuate and was approved 
by state emergency officials. This decision necessitated careful coordination with other community resources. Lists were made of which residents were going to each temporary shelter; families and others were notified if possible. Three other facilities in the area were able to take 25 residents and two sent vans for transportation. Sue Wells, the social worker, was assigned the task of preparing the residents for relocation to these settings. Several certified nursing assistants helped to pack clothing and a few personal items. Ten of the frailest residents were transported to the local hospital, which had sustained only minor damage. Fourteen residents could be temporarily housed with their family members. This left 61 residents who were transported to the nearby community college auditorium, where they were temporarily sheltered and cared for by the school's nursing students. The entire evacuation took about 10 hours and included the cooperation of two vans, two bus companies, four ambulances, and numerous volunteers. Sue Wells was given a copy of the resident list and where they had been transported, and provided follow-up phone calls to families. The 61 residents were temporarily moved to six different nursing facilities in the area. Sue remained in contact with the facilities and families during the next month, while the facility was repaired.

\section{WHAT ARE SOME OF THE AGENCIES INVOLVED WITH DISASTERS AND LONG-TERM CARE FACILITIES?}

The following is a list of agencies and their acronyms that are associated with disasters:

CMS-Centers for Medicare \& Medicaid Services

DHS-Department of Homeland Security

DMAT-Disaster Medical Assistance Team

DOD-Department of Defense

DOT-Department of Transportation

FEMA-Federal Emergency Management Agency

NDMS-National Disaster Medical System

NRP-National Response Plan

\section{HOW DO PANDEMICS AFFECT NURSING FACILITIES?}

When Laura Leonard pulled up to the parking lot at her nursing facility, she knew it was going to be a rough day. There was an ambulance at the front door and a hearse at the backdoor. The administrator greeted her 
at the employee's entrance and told her that she would be responsible for contacting families about the newly diagnosed positive cases of coronavirus 2019 (COVID-19) in the facility. She was handed a list and no further instructions. Prior to this day, the facility boasted of not having any positive COVID-19 cases in the building. This was at the end of March 2020, at the beginning of the pandemic.

Pandemics are epidemics of disease that occur worldwide or over a large expanse, crossing international borders, and that affect a large number of people. History informs us that plagues and pandemics have been around since prehistoric times. Looking at the history of pandemics, we can see waves of viruses and infections that have ravaged populations over time. Some of these diseases use similar vectors (intermediate parasites), such as mosquitoes, and others use the bodily fluids of the infected person to pass on the infection to others. Some of the pandemics of the past include the bubonic plague, smallpox, yellow fever, the Russian flu (1889-1890), polio, the Spanish flu (1918-1920), the Asian flu (1957-1958), AIDS (1981-present), N1H1 swine flu (2009-2010), Western African Ebola epidemic (20142016), and Zika virus (2015-present; History.com Editors, 2020).

We are all aware of this latest pandemic of COVID-19, a type of coronavirus. Close proximity to others in settings where there are large groups of people gathered, such as hospitals, nursing facilities, assisted living settings, cruise boats, jails, and so on, has demonstrated that infection for these contagious diseases can run rampant. Nursing homes have also had experience with and addressed some other contagious infections such as vancomycin-resistant Enterococci, methicillin-resistant Staphylococcus aureus, and Clostridioides difficile. For seriously infectious pandemics, greater precautions are needed in facilities and include the community interaction with the residents as well.

Since January 2020, we have learned a good deal about how easily this particular virus is spread via contact with exhaled airborne droplets from an infected person. Key guidance and protection for residents, staff, and community safety is very important in managing contagion and spread. In addition, the social worker should have an active role in advocating for resident quality of life, including enhancement of communication/visitation, appropriate activities to assist with dispelling isolation, and adequate staffing.

\section{WHAT CAN BE DONE IN THESE SETTINGS TO MAKE THEM SAFER FOR ALL CONCERNED?}

In response to the need for guidance and recommendations for this particular pandemic, the Coronavirus Commission for Safety and Quality in 
Nursing Homes was created through the CMS. The Commission made several major points: Identify best practices, recommend best practices as exemplars of rigorous infection control practices and facility resilience, and leverage new data sources to improve upon existing infection control policies and enable coordinated actions (Coronavirus Commission on Safety and Quality in Nursing Homes, 2020).

Some of the highlighted action steps noted by this Commission specifically for nursing homes include:

- regular testing and screening of residents and staff;

- adequate access to personal protective equipment (PPE);

- cohorting: emphasizing the social and emotional health of the residents to balance psychological safety with infection prevention and control;

- resident visitation: right to visitation and clarification of modifications to this right to visit for each phase of the pandemic;

- communication: development of standard templates for progress notes and email blasts to residents, families, and resident representatives;

- workforce ecosystem: address relief funds for hazard pay and guidance for certified nursing assistant training;

- technical assistance for quality assurance performance improvement (QAPI) tools;

- facilities: the physical environment and improvements to reduce/limit the spread of transmissible diseases.

\section{WHAT IS THE ROLE OFTHE SOCIAL WORKER IN A PANDEMIC?}

There are multiple roles for the social worker before, during, and after a pandemic. One of the roles that social workers fulfill is to provide and maintain timely accurate communication, particularly when visitation is curtailed. Through telephone conversations, virtual team meetings, and emails with the residents, families, legal representatives, and the larger community, the social worker can help convey important, timely information about resident status and respond to concerns. When staff are occupied with care, the social worker can act as a liaison, help with information about resident status, and reinforce advocacy.

For families, responsible parties, friends, and others, resident-restricted visitation is a stressful time for everyone. Some residents and community 
members are more frustrated about limited visits than others. It is important for the social worker to respect their level of irritation without becoming impatient. They can help ensure the greatest access within the safety guidelines of the local, state, and federal agencies and explain the guidelines as often as needed. Use the technique of "universalization," which means we are all going through these frustrating times together, to describe circumstances, as this can dispel the notion that restrictions/constraints are aimed at a person or family.

It is also helpful for the social worker to make suggestions as to how families/others can maintain positive contact with the resident when quarantine prevents visits. Families can send daily/weekly greeting cards, provide printed pictures of family members engaged in various activities, provide special food treats, sew/make colorful quilts, or provide little fun gifts as room decorations. These can help the resident know that they are not forgotten. When permitted, food deliveries can also be a part of the connection that residents have to the outside; coffee, donuts, homemade cookies, and even pizza can brighten a resident's day. The social worker can advocate for these treats as a part of connecting the residents to the community. Visits made through windows and in open areas with masks worn are another way for families and loved ones to connect with their resident.

\section{HOW CAN THE SOCIAL WORKER ASSIST FAMILIES DURING THE PANDEMIC WHO ARE GRIEVING THE LOSS OF A LOVED ONE?}

Death during a pandemic is very difficult for families because of restricted visiting and questions that pertain to how the person's last days/hours were spent. The social worker can answer family questions by offering details that help relieve their concerns that proper pain relief was given and by indicating that the loved one was not alone during their final hours. For some, the death of a beloved family member is difficult in any circumstances and the restrictions of the pandemic are an added burden.

The social worker can help advocate for "secure visiting" at the end of life when possible. These visits can be brief with the family wearing protective gear. In some cases, plastic coverings have been used that allow for the individual to be touched and hugged without breaking infection-control guidelines.

At the same time, this does not always lead to families being satisfied with the response of the facility, nor resolve the issue of dying. For example, a social worker received an angry, bereaved message on her weekend 
voicemail that indicated that the daughter blamed the facility for her father's death: "You killed my father, the love of my life." The daughter further stated that she did not want any contact with the facility or its staff. The social worker was saddened by this accusation but could not respond because of the daughter's demand for "no further contact." She shared the voicemail with her administrator and director of nurses and discussed ways that they could improve communications, for example, more personal phone calls with family members with updates, encouraging communication through Zoom meetings with the family, and trying to identify families who are struggling with the pandemic so as to provide outside counseling resources.

\section{WHAT CANTHE SOCIAL WORKER EXPECT FROM THE FACILITY WITH REGARDTO PERSONAL PROTECTIVE EQUIPIMENT?}

As with other staff members involved with direct care, the facility should be providing good masks, protective eye wear, and, if needed, gowns and gloves, combined with extensive training for proper use and disposal of these items. Social workers should also have access to cleaning supplies for the office computer, phone, and be situated in an office that provides appropriate ventilation and safe social distancing. As with other employees, the social workers should be trained in best practices for overall infection control. Social workers should know that their role is an administrative one, rather than a "hands-on" role with residents who are contagious. If actively infected residents are identified, the social worker should be completing their scope of practice in the safest manner possible. The social worker can work with the facility staff development coordinator, the director of nurses, and the administrator in order to achieve the greatest benefits with minimal risks.

\section{WHAT ABOUT THE SOCIAL WORKER, PERSONAL PROTECTIVE EQUIPMENT, AND COMMUNICATION?}

Communicating while wearing PPE is difficult. Masks, eye protection, hair coverings, gloves, and gowns create a barrier between social workers and older adults. "Social workers are making moment-by-moment decisions about how to exercise the core ethical principles of the profession. One social worker discussed her decision to either wear her PPE or frighten her threeyear-old client in foster care; in the end, she decided her duty to her client took priority and took off her mask" (Abrams \& Dettlaff, 2020, pp. 302-303). There has been little written about PPE and older adults; however, we know that those with hearing loss are affected by not being able to read a person's 
lips. One may need to be closer than safe distancing recommendations suggest in order to be heard. Social workers are challenged by the lack of touch of a comforting hand on a resident who is upset. The challenges in working safely with those with dementia can also be difficult because they often don't understand the limitations of social distancing and mask wearing.

Social workers can utilize hearing-assistive devices to enhance communication. They can also be creative with the PPE, using bright colors for hair coverings; utilizing creative, colorful masks; or even decorating the masks. Residents can recognize and associate the social worker from others through these minor alterations.

\section{WHAT OTHER OPPORTUNITIES ARE THERE FOR SOCIAL WORK INTERVENTIONS DURING A PANDEMIC?}

Pandemics are stressful for all the staff in a nursing facility. Social workers are particularly well positioned to assist with the post-stress that staff experience with the loss of residents. Both nurses and certified nursing assistants may feel the effects of losing a resident to COVID-19 weeks or months later when another resident dies from another cause. For example:

Mary Hart, a licensed nurse, worked through the pandemic and witnessed multiple deaths. "I would come into work, and these residents would seem $O K$, then all of a sudden they would develop severe respiratory symptoms. I would turn my back to get something, and they just died." Many of the residents with whom she worked had been residents of the facility before the pandemic. She recalled that, during the height of the pandemic, a long-term resident who was young, in his 40's, who had locked-in syndrome (pseudocoma) was initially denied ambulance service to the hospital. She argued with the ambulance attendants and successfully moved her patient. She was very protective of the residents and their care needs. Her more recent concerns were about a death in the facility and her anger at the attending physician who made the decision not to send the post-COVID recovering resident to the hospital even though the resident did not have a "do not hospitalize" order. "They shouldn't have died."

In situations like this, the social worker can provide support to the nurse by listening and pointing out their positive strong advocacy role. It may also be appropriate to encourage nurses to seek additional help, either with the facility human resources department or with private counseling referrals, for the trauma they have experienced. In some cases, the facility can begin 
a support group for the staff around these issues that the social worker can lead or co-lead with a social work consultant.

In summary, during disasters and pandemics, the social worker's role encompasses broad areas. Helping residents, families, and staff with concrete supportive interventions and building and sustaining positive connections among the facility, residents, and community are essential to social work. Outreach to families by providing them with information about the status of their loved ones in the facility cannot be underrated. Disasters and pandemics are incredibly stressful for residents and the community; the social worker can make a difference in their facility roles through support, advocacy, and reassurance.

\section{REFERENCES}

Abrams, L. S., \& Dettlaff, A. J. (2020). Voices from the frontlines: Social workers confront the COVID-19 pandemic. Social Work, 65(30), 302-305. https://doi.org/10.1093/sw/ swaa030.

Centers for Medicare \& Medicaid Services. (2008, October). Draft emergency preparedness guide: For state survey agencies, health care providers, and partners. U.S. Department of Health and Human Services. https://www.hsdl.org/?view\&did=705731.

Cornell Law School. (2000). Legal Information Institute. The Stafford Act. 42 U.S.C. \$5122(2). https://www.law.cornell.edu/uscode/text/42/5122.

Coronavirus Commission on Safety and Quality in Nursing Homes. (2020, September). Commission final report. https://edit.cms.gov/files/document/covid-final-nh-commission -report.pdf.

Goolsby, C. A., \& Mothershead, J. (2010). Disaster planning. emedicine. http://emedicine .medscape.com/article/765495.

History.com Editors. (2020). Pandemics that changed history. Retrieved September 20, 2020 from https://www.history.com/topics/middle-ages/pandemics-timeline.

Joint Commission. (2005). Standing together: An emergency planning guide for America's communities. Joint Commission on Accreditation of Healthcare Organizations. www .jointcommission.org/assets/1/18/planning_guide.pdf

Langford, T. (2009, June 4). Settlement over Hurricane Rita bus fire brings closure. Houston Chronicle. https://www.chron.com/news/houston-texas/article/Settlement-over -Hurricane-Rita-bus-fire-brings-1736019.php.

Lubit, R. H. (2012). Acute treatment of disaster survivors. http://emedicine.medscape.com/ article/295003-overview.

Parker, L. (2005, November 28). What really happened at St. Rita's? USA Today. http:// globalag.igc.org/armedconflict/countryreports/americas/happened.htm

Toner, J. A., Mierswa, T. A., \& Howe, J. L. (2010). Health, disaster, and emergency preparedness. Springer Publishing Company.

U.S. Government Accountability Office. (2006, July). Disaster preparedness: Limitations in federal evaluation assistance for health facilities. Report to Congress. GAO-06-826. https:// www.gao.gov/products/gao-06-826. 